\title{
COVID and Lung Cancer
}

\author{
Luana Calabròn ${ }^{1,2} \cdot$ Giulia Rossi $^{1} \cdot$ Alessia Covre $^{1,2,3} \cdot$ Aldo Morra $^{4} \cdot$ Michele Maio ${ }^{1,2,3,5}$
}

Accepted: 2 September 2021 / Published online: 22 October 2021

(c) The Author(s), under exclusive licence to Springer Science+Business Media, LLC, part of Springer Nature 2021

\begin{abstract}
Purpose of Review Since the past year, the fast spread of coronavirus disease 2019 (COVID-19) has represented a global health threat, especially for cancer patients, that has required an urgent reorganization of clinical activities. Here, we will critically revise the profound impact that the pandemic has generated in lung cancer patients, as well the most significant challenges that oncologists have to face to maintain the highest possible standards in the management of lung cancer patients in the pandemic era.

Recent Findings Evidences suggested a higher susceptibility and mortality of lung cancer patients due to COVID-19. The hard management of this patient population has been also due to the potential cross interference of anti-tumor drugs on SARS-Cov-2 infection and to the differential diagnosis between COVID-19 pneumonitis and drug-related pneumonitis. Summary COVID-19 pandemic has generated a profound reshaping of oncological activities and the development of recommendations by the oncology scientific community to prioritize anti-tumor treatments for lung cancer patients.
\end{abstract}

Keywords COVID-19: SARS-CoV-2; Lung cancer · Drug-toxicity pneumonitis

This article is part of the Topical collection on Lung Cancer

Luana Calabrò

1.calabro@ao-siena.toscana.it

Giulia Rossi

giulia.rossi@ao-siena.toscana.it

Alessia Covre

alessiacovre@gmail.com

Aldo Morra

aldo.morra@synlab.it

Michele Maio

maio@unisi.it

1 Center for Immuno-Oncology, Medical Oncology and Immunotherapy, Department of Oncology, University Hospital of Siena, Siena, Italy

2 EPigenetic Immune-Oncology Consortium Airc (EPICA), Viale Mario Bracci, 16; 53100 Siena, Italy

3 University of Siena, Siena, Italy

4 IRCCS SDN, Naples, Italy

5 Fondazione NIBIT Onlus, Siena, Italy

\section{Introduction}

Since the first case in Wuhan in late 2019, a novel coronavirus disease 2019 (COVID-19), rapidly spread across the globe, leading the World Health Organization to declare a pandemic on March 11, 2020 [1]. The causal agent of COVID-19 is SARS-CoV-2, a newly identified strain of the single-stranded RNA coronavirus, that shows high structural homology to the SARS coronavirus (SARS$\mathrm{CoV}$ ) and Middle East Respiratory Syndrome (MERS$\mathrm{CoV}$ ), responsible for the 2002 and 2012 respiratory pandemic, respectively [2]. Unfortunately, in terms of death rates, COVID-19 has demonstrated to be the worst pandemic compared to the previous CoVs ones [3, 4]. Consistently, as of February 6, 2021, more than 105 million of confirmed infected cases and more than 2.3 million of deaths have been globally reported; unfortunately, these figures are estimated to increase (https://coronavirus.jhu. edu/). Consequently, COVID-19 has been considered a public health emergency of major international concern that has required since the past year an urgent reorganization of hospital wards, mostly dedicated to intensive care, together with a modulation of clinical activities, to cope with the growing number of SARS-CoV-2 infected patients requiring hospitalization and intensive supportive 
of care [5,6]. Overall, the in-hospital mortality due to COVID-19 has been reported up to $25 \%$; noteworthy, mortality rate may vary between countries based on resource limitations, geography, literacy, population, and political factors $[1,7 \bullet \bullet]$. Interestingly, the public health interventions have not changed significantly since the $1918 \mathrm{flu}$ pandemic and include home quarantine after infection, restricting mass gatherings, travel restrictions, and social distancing that temporarily reduce rates of transmission. However, the risk of restarting follows when these interventions are lifted, and this is exactly what has happened leading to the second wave of the COVID-19 pandemic [8].

Clinical manifestations of COVID-19 are very heterogeneous and strictly dependent on the nature of the interaction between SARS-CoV-2 and host $[9,10]$. Along this line, SARS-CoV-2 dependent factors can include genetics, viraemia title, and virulence, while host-dependent factors may include genetic characteristics, age, gender, humoral and cellular immune system health, and, finally, comorbidities. In the majority of infected patients, clinical manifestations of COVID-19 are mild and include cold, fever, cough, dysgeusia, anosmia, or other nonspecific symptoms or signs [9]. More severe symptoms, ranging from severe pneumonia, to acute respiratory distress syndrome, septic shock, and/or multiorgan failure, may occur more frequently in patients affected by comorbidities, such as chronic disease or cancer [ $7 \bullet \bullet]$. The advanced phase of COVID-19 infection usually associates with blood test alterations, including lymphopenia, increased leukocyte count and neutrophil-to-lymphocyte ratio, serum levels of C-reactive protein, procalcitonin, lactate dehydrogenase, creatinine, directed bilirubin, and transaminases, and most of them associate with a poor prognosis $[11 \bullet \bullet]$.

Although a plethora of treatments have been evaluated or are currently under clinical development, there are still no drugs used in the clinical practice that have proven truly effective. Therefore, the clinical management of COVID-19 infection is mainly based on symptomatic agents, antivirals, as well as organ support in the intensive care unit (ICU) for critically ill patients $[11 \bullet \bullet, 12,13]$. The search for effective vaccines for SARS-CoV-2 has been in full swing by pharmaceutical companies in the last months. Consistently, a variety of vaccines have been already developed (Table 1), and a large-scale vaccination, among the widest in the history, has globally started since December 2020, though no definite information is available regarding the efficacy of these vaccines against the recently identified SARS-CoV-2 variants that are rapidly spreading worldwide (https://www. who.int/publications/m/item/draft-landscape-of-covid-19candidate-vaccines).

\section{COVID-19: Pathophysiology and Immunology}

SARS-CoV-2 spreads primarily via respiratory droplets and aerosol during close face-to-face contact. Once inside the body, SARS-CoV-2 targets the upper and lower airways cells, such as nasal and bronchial epithelial cells, and pneumocytes, via viral structural spike $(\mathrm{S})$ protein that binds to the functional angiotensin-converting enzyme 2 (ACE2). The entry of SARS-CoV-2 into host cells is mediated by the type 2 transmembrane serine protease (TMPRSS2) that promotes viral uptake by cleaving ACE2 and by activating the SARS-CoV-2 S protein $[14 \bullet, 15]$. Both ACE2 and TMPRSS2 are highly expressed in lung alveolar type II cells, but also in extrapulmonary organs, including digestive tract, liver, kidney, cardiovascular system, and brain, thus explaining an involvement of these organs in the clinical manifestations and/or complications of the infection in a proportion of infected subjects [16, 17].

Although a plethora of COVID-19 studies have been published in the past year in an effort to rapidly unravel the pathogenetic mechanism of SARS-CoV-2 and to identify potential therapeutic approaches, the pathophysiology of COVID-19 remains largely unknown. Recent investigations suggest that SARS-CoV-2 induces a host dysregulated immune response that can translate in severe organ damages [10]. Indeed, in the early phase of the infection, the SARSCoV-2 virus is mainly localized in the upper respiratory tract, thus generating a strong host immune response that involves the release of chemokines and interferons (IFNs), sufficient in the majority of subjects to contain the spread of infection. Unfortunately, in about one-fifth of all infected patients, the viral infection progresses and involves the lower respiratory tract leading to severe symptoms and complications [15]. Consistently, the viral infection of pneumocytes induces the release of proinflammatory cytokines, including interleukins, tumor necrosis factor- $\alpha$, IFN- $\lambda$ and IFN$\beta$, CXCL-10, monocyte chemoattractant protein-1, and the macrophage inflammatory protein-1 $\alpha$ [15]. If not resolved, this exacerbated cytokine production, so-called cytokine storm, acts as a chemoattractant for a variety of immune cells whose activation on one side fights off the virus while on the other side contributes to sustain inflammation and lung injury [15]. The persistent inflammation and lung injury can lead to both a diffuse alveolar damage, disruption of epithelial-endothelial barrier integrity, with consequent respiratory distress syndrome, and an activation of coagulation with consequent high incidence of thrombotic complications, that can finally contribute to a multiorgan failure with potentially lethal consequences $[10,15]$.

Immunologically, in addition to the innate immune response, both humoral and cellular immune responses are 
Table 1 COVID-19 vaccine approved by at least one country

\begin{tabular}{lll}
\hline $\begin{array}{l}\text { Vaccine name } \\
\text { Developers }\end{array}$ & Type Approved \\
\hline
\end{tabular}

\begin{tabular}{lll}
\hline EpiVacCorona & Protein subunit (peptide antigen) & Russia
\end{tabular}

Vector State Research Centre of

Virology and Biotechnology

\section{BNT162b2/CMIRNATY Nucleoside-modified mRNA}

BioNTech/Pfizer

mRNA-1273

Moderna

Ad5-nCoV

CanSino Biologics

Sputnik V

Gamaleya Research Institute

AZD1222 Oxford/AstraZeneca

Covishield (ChAdOx1_nCov-19)

Serum Institute of India

Covaxin

Bharat Biotech

BBIBP-CorV

SARS-Cov-2 Vaccine (Vero Cell)

Sinopharm

Inactivated (InCov)

Sinopharm

CoronaVac

Sinovac Biotech

Inactivated
mRNA-based vaccine encapsulated in lipid nanoparticle (LNP)

Recombinant novel coronavirus Vaccine (adenovirus type 5 vector)

Non-replicating viral vector

Human adenovirus vector-based COVID-19 vaccine Non-replicating viral vector

Recombinant replication defective chimpanzee adenovirus expressing the SARS-Cov-2 S surface glycoprotein

Non-replicating viral vector

Recombinant ChAdOx1 adenoviral vector encoding the spike protein antigen of the SARS-CoV-2 Non-replicating viral vector

Inactivated

Inactivated

Inactivated
Bahrain, New Zealand, Saudi Arabia, Switzerland, Argentina, Australia, Canada, Chile, Colombia, Costa Rica, Ecuador, European Union, Iceland, Iraq, Israel, Jordan, Kuwait, Lebanon, Malaysia, Mexico, Mongolia, Norway, Oman, Panama, Peru, Philippines, Qatar, Serbia, Singapore, Tunisia, United Arab Emirates, UK, USA, South Korea

Switzerland, Canada, European Union, Iceland, Israel, Mongolia, Norway, Qatar, Singapore, UK, USA

Mexico, China

Russia, Algeria, Argentina, Armenia, Bahrain, Belarus, Bolivia, Bosnian Serb Republic, Guinea, Hungary, Iran, Kazakhstan, Lebanon, Mexico, Mongolia, Myanmar, Nicaragua, Pakistan, Palestinian Authority, Paraguay, Serbia, Tunisia, Turkmenistan, United Arab Emirates, Venezuela

Algeria, Argentina, Bangladesh, Bhutan, Brazil, Chile, Dominican Republic, Egypt, El Salvador, European Union, Iceland, India, Iraq, Kuwait, Maldives, Mexico, Mongolia, Morocco, Nepal, Norway, Pakistan, Philippines, Seychelles, Sri Lanka, South Africa, South Korea, Thailand, UK

Argentina, Bahrain, Bangladesh, India, Maldives, Morocco, Nepal, South Africa, Sri Lanka

India

Bahrain, China, United Arab Emirates, Cambodia, Egypt, Hungary, Iraq, Jordan, Pakistan, Peru, Serbia, Seychelles

China, United Arab Emirates

China, Azerbaijan, Brazil, Chile, Colombia, Indonesia, Laos, Turkey, Uruguay

Last Updated 12 February 2021

https://www.who.int/publications/m/item/draft-landscape-of-covid-19-candidate-vaccines

https://covid19.trackvaccines.org/vaccines/

involved in the elimination of the virus [18]. Consistently, it has been reported a robust B cell response to SARS$\mathrm{CoV}-2$, as evidenced by the rapid detection of virus-specific $\operatorname{IgM}, \operatorname{IgG}$ and $\operatorname{IgA}$, and neutralizing $\operatorname{IgG}$ antibodies (nAbs) in the days following infection. Sero-conversion occurs approximately between 7 and 14 days after the onset of symptoms in the majority of infected patients, and antibody titers persist in the weeks following virus clearance [19-22]. Similarly, the cellular adaptive immune response, mainly sustained by helper and cytotoxic $\mathrm{T}$ cells, plays a crucial role in the clearance of viral-infected cells [23]. Though mechanisms utilized by SARS-CoV-2 to escape the host's adaptive immune response and to induce a dysregulation of host immune response are not yet properly clear, evidence from SARS-CoV and MERSCoV reported a depletion of both CD4 and CD8 T cells and the induction of $\mathrm{T}$ cell apoptosis that may explain the peripheral lymphopenia, a common laboratory hallmark of these infections, usually observed in moderate and severe COVID-19 subjects [24-27]. Noteworthy, the extent of lymphopenia, most striking for CD8 $\mathrm{T}$ cells in patients admitted to ICU, correlates with COVID-19-associated 
disease severity and mortality, while it recovers as patients improve $[11 \bullet \bullet, 24,25,28]$. Supporting these findings, a dysregulation of $\mathrm{T}$ cells, expressing on their surface markers of activation (including HLA-DR, CD69, CD38, and CD44), exhaustion (such as mucin-3, programmed cell death protein (PD)-1 and natural killer group 2 member A), and/or co-stimulatory and inhibitory molecules (such as OX-40 and CD137, cytotoxic T lymphocyte A-4 (CTLA-4), TIM3, TIGIT), has been reported in subjects with severe SARS-CoV-2 infection [24, 29, 30]. Moreover, cellular functionality has been shown to be impaired in both CD4 and CD8 T cells of critically ill patients, with reduced frequency of polyfunctional $\mathrm{T}$ cells $[24,25]$.

Overall, as a consequence of the dysregulation of host's immune system, that is unable to eradicate SARS-CoV-2 virus, the infection may spread within all the body with the concurrent manifestation of viraemia and septic shock $[10,24]$.

\section{The Implication of the COVID on Lung Cancer}

The impact of the COVID-19 pandemic in oncology field has been really dramatic both for the hard management of cancer patients in this chaotic period, and the intricate relationships that may occur between cancer and susceptibility to SARS-CoV-2 infection. Concerning this latter aspect, as known, cancer patients have in general a higher sensitivity and susceptibility to adverse outcomes from infections compared to general population; therefore, they may be vulnerable to SARS-CoV-2 too [10]. Consistently, increasing evidence reports severe outcome from COVID-19, including higher rates of hospitalization and death, in cancer patients $[31,32 \bullet, 33]$. This is mainly due either to their chronic immunosuppressive state induced by tumor cells or exacerbated by myelosuppresive therapies (such as cytotoxic agents or radiotherapy) which in turn maintain a local and systemic inflammation, and may lead/predispose to overlapping infections, or to treatment-related toxicity, including cardiovascular disease $[34,35]$. Along this line, it has been observed an association between severity of COVID19 and subjects with an advanced phase of cancer disease and a poor ECOG performance status. Additionally, aging, obesity, and metabolic syndrome are predisposing factors for cancer and represent comorbidities that may influence susceptibility to SARS-CoV-2 infection and severity of its complications [36].

In this complex scenario, the impact of SARS-CoV-2 is even more dramatic in patients with thoracic neoplasms, as they are in most cases elderly, often suffering from concomitant obstructive or restrictive lung diseases, which expose them to a greater risk of an unfavorable outcome in case of SARS-CoV-2 infection. Moreover, it has been demonstrated an aberrant expression of ACE2 in lung carcinoma compared to normal tissues, regardless of the stage of disease, making this patient population even more vulnerable to COVID-19 [37]. In support of these findings, a retrospective analysis reported an estimated risk of infection to SARS$\mathrm{CoV} 2$ and severe or fatal complications of about 2.31 times higher in lung cancer patients than general population, or compared to patients with other malignancies [38, 39]. In an Italian study, lung cancer patients showed a four-fold risk of death due to COVID-19 infection [40]. Similarly, Luo and colleagues reported a longer course of COVID-19 and more severe complications in lung cancer patients than the general US population [41]. In particular, two-thirds of cancer patients required hospitalization, and one-quarter of them died. Smoking status and chronic obstructive pulmonary disease were the main determinants of severe outcome from SARS-CoV-2 infection [41]. Consistent with these analyses are the results of the TERAVOLT study conducted in 200 patients with thoracic malignancies and with concomitant COVID-19 infection. Preliminary results showed a mortality rate of 33\%, and an association among older patients (over 65 years), current or former smoking, presence of comorbidities, and risk of death was observed [32•].

Overall, although these data suggest that lung cancer may be an independent risk factor for severe COVID-19, prospective studies are needed to fully elucidate which role the neoplastic disease may play in this infective disease.

Adding complexity to this already complex/intricate scenario is the potential cross-interference of COVID-19 and lung cancer treatments, in which, unfortunately, no conclusive data are currently available. In this context, among therapeutic approaches largely utilized for locally advanced and/ or metastatic lung cancer patients, cytotoxic agents, tyrosine kinase inhibitors (TKIs), and radiotherapy could play a role due to their pleiotropic effects on the patient's immune system [42••]; on the other hand, immune checkpoint inhibitors (ICI), that in the last years have represented a keystone in the therapeutic armamentarium of thoracic malignancies, may play a potentially more relevant role in view of their profound immunomodulatory activity [42••]. Indeed, as above reported, in the early phase of COVID-19, it has been observed an up-regulation of $\mathrm{T}$ cell subsets expressing surface markers of early activation, or PD-1 that identifies a subset of $\mathrm{T}$ cell exhaustion; both these $\mathrm{T}$ cell subpopulations could be expression of an early phase of $\mathrm{T}$ cell priming

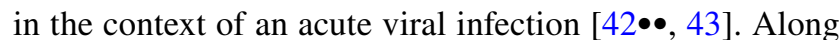
this line, targeting CTLA-4 or PD-1/PD-ligand (L)- 1 axis quickly induces an expansion of CD4 and CD8 pool of T cells and re-invigorates exhausted T cells, respectively [44]. Then, these findings could support a potential therapeutic role of ICI against the dysfunction of the host's immune system induced by SARS-CoV-2 infection. Indeed, in one 
potential mechanistic scenario, ICI therapy may ameliorate the early phase of COVID-19 by contributing to viral clearance also through the re-activation of PD-1 positive viral epitope-specific T cells [42••]. Conversely, the therapeutic targeting of ICI, through the promotion of different immune activation mechanisms and increased levels of circulating cytokines, could represent a clinical issue in the early phase of SARS-CoV-2 infection, as it may favor a worsening of COVID-19 towards its more aggressive inflammatory stage $[42 \bullet \bullet]$. On the other hand, supporting the safety role of ICI during COVID-19 pandemic, in a variety of clinical studies conducted in cancer patients affected by a concomitant virus infection, such as HIV, HBV, and/or HCV, and treated with ICI, both toxicity and efficacy rates were similar to those observed in patients without viral infection; moreover, no

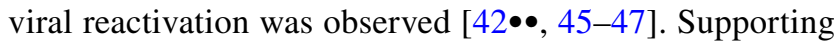
these findings, results from the TERAVOLT study, though still preliminary, suggest that the type of systemic therapy, including targeted therapy, chemotherapy, and ICIs, did not affect survival in patients with COVID-19 [32•].

Overall, though not yet conclusive, data so far generated support the safety of PD-(L)1 blockade with or without chemotherapy and/or TKIs, and the lack of association with an increased severity or mortality by COVID-19 [10].

An additional major challenge in the COVID-19 pandemic consists in making a rapid and correct differential diagnosis among SARS-CoV-2-induced pneumonitis and drug-induced lung toxicity. Indeed, this latter may present with symptoms often not specific, consisting mainly of cough (or its worsening), chest pain, dyspnea, and fever, that are very similar to those observed in the SARS-CoV-2 infection (Table 2) [5, 48]. Along this line, also radiological imaging of drug-related toxicity may overlap with that typical of COVID-19-induced pneumonia, thus hindering the discrimination of these clinical entities (Table 2) [5]. Chest computed tomography (CT) is the imaging modality of choice, for the evaluation of pneumonitis in patients with lung cancer underwent target therapy or immunotherapy, and it is also the most sensitive method for diagnosis of COVID-19 pneumonitis, even in initial stages of the illness [15]. Concerning ICI-related lung toxicity, a wide spectrum of imaging manifestations has been reported, such as ground glass (GG) areas and/or consolidations that occurs in approximately $70-80 \%$ of cases, usually with no specific distribution (Fig. 1a), septal thickening, and traction bronchiectasis in about $15-20 \%$ of patients, or features of acute interstitial pneumonitis (AIP) including consolidations and volume loss that depend on severity of toxicity; additionally, lesions are mostly multifocal and involve the

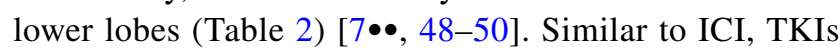
can induce lung toxicity, particularly interstitial lung disease (ILD), in approximately 4\% of treated patients [51]. The CT patterns of TKI-associated ILD include nonspecific areas of GG opacity, multifocal areas of air space consolidation, patchy distribution of GG accompanied by interlobular septal thickening and extensive bilateral GG, or air space consolidations with traction bronchiectasis and small centrilobular nodes (Table 2) [52]. Similar to radiological imaging observed in drug-related lung toxicity, CT features of typical COVID-19 pneumonitis include bilateral subpleural areas of GG that are mainly located in the lower lobe, frequently reported to have round morphology (Fig. 1b) and they are

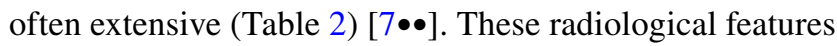
seem to be dependent on disease duration; indeed, the onset
Table 2 Differential diagnosis between COVID-19-related pneumonitis and drugs (ICI or TKI)-related pneumonitis: clinical (A) and radiological (B) characteristics

\begin{tabular}{|c|c|c|c|c|c|c|c|}
\hline \multicolumn{4}{|c|}{ (A) Main clinical characteristic } & \multicolumn{4}{|c|}{ (B) Main radiological characteristics } \\
\hline & COVID-19 & ICI & TKI & & COVID-19 & ICI & TKI \\
\hline Dyspnea & $\mathrm{X}$ & $X$ & $X$ & GG areas & $X$ & $\mathrm{X}$ & $X$ \\
\hline Cough & $X$ & $X$ & $\mathrm{X}$ & Consolidations & - & $X$ & $X$ \\
\hline Chest pain & $X$ & $X$ & $\mathrm{X}$ & Septal thickening & $\mathrm{X}$ & $X$ & $X$ \\
\hline Fever & $X$ & $X$ & $\mathrm{X}$ & Traction bronchiectasis & - & $X$ & $\mathrm{X}$ \\
\hline Hypoxiemia & $X$ & $X$ & $\mathrm{X}$ & Features of AIP/ILD & & $X$ & $X$ \\
\hline Myalgia & $X$ & $-*$ & - & Multifocal manifestations: & $\mathrm{X}$ & $\mathrm{X}$ & $\mathrm{X}$ \\
\hline Fatigue & $\mathrm{X}$ & - & - & - > Peripheral & - & $X$ & $\mathrm{X}$ \\
\hline Headache & $\mathrm{X}$ & - & - & - > Lower lobe & $\mathrm{X}$ & $X$ & $\mathrm{X}$ \\
\hline Anosmia & $\mathrm{X}$ & - & - & - > subpleural & $X$ & - & - \\
\hline Dysgeusia & $\mathrm{X}$ & - & - & Bilateral manifestations & $\mathrm{X}$ & $X$ & $\mathrm{X}$ \\
\hline Abdominal pain & $X$ & $-*$ & - & Vascular thickening & $\mathrm{X}$ & - & - \\
\hline Diarrhea & $X$ & $-*$ & $-*$ & Small centrilobular nodules & - & - & $\mathrm{X}$ \\
\hline Runny nose & $X$ & - & - & Honeycombing & - & - & $X$ \\
\hline
\end{tabular}

COVID-19 coronavirus disease 2019, ICI immune checkpoint inhibitor, TKI tyrosine kinase inhibitor, GG ground glass, AIP acute interstitial pneumonitis, ILD interstitial lung disease

${ }^{*}$ As a further immune-related adverse event 


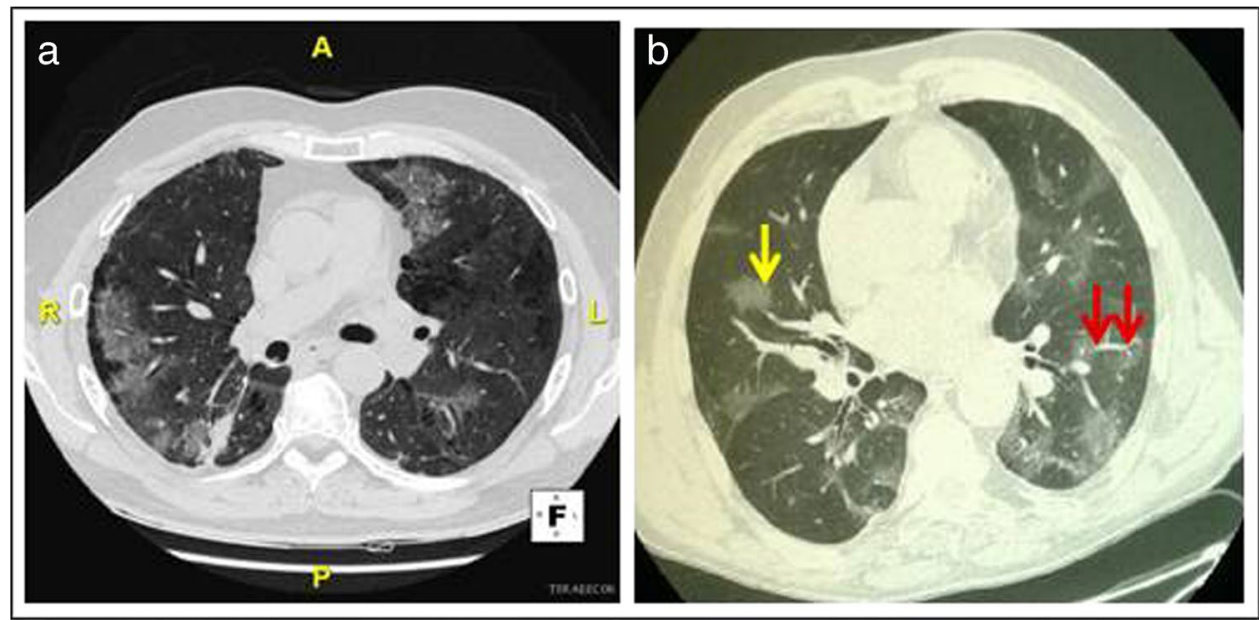

Fig. 1 CT scans of pneumonia due to a immune checkpoint inhibitor therapy or b COVID-19: a Axial lung image (without intravenous contrast) of an immune checkpoint inhibitor-treated 63-year-old man with metastatic non-small cell lung cancer, showing ground glass opacities, with nonrounded morphology and no specific distribution, associated to a right small area of consolidation. b Axial lung image

of thickened intralobular septa in the areas of GG occurs approximately after 8-10 days of COVID-19 and results in a crazy paving pattern. Pulmonary vascular abnormalities such us vascular dilation are also often found in COVID-19 pneumonia [53]. When infection progresses, areas of consolidation can develop both in pre-existent GG areas but also in lung areas that were previously not involved [7••]. In the healing stage of disease, features of organizing pneumonia can be also seen $[7 \bullet \bullet$. Atypical CT patterns of COVID-19 pneumonitis mostly consist in pseudo-nodular consolidations that suggest an organizing pneumonia, or in focal area of patchy opacities surrounded by a peripheral ring with consolidation (so-called reversed halo sign) that are often

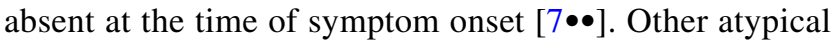
presentations include unilateral presentation and apical predominance or peribronchovascular disease $[7 \bullet \bullet]$. To standardize assessment of un-enhanced CT in patient with suspected COVID-19 pneumonia, CO-RADS (COVID-19 reporting and data system) have been developed [54]. Furthermore, it has been reported a high incidence of pulmonary emboli in subjects with COVID-19, thus suggesting the inclusion of a CT-angiography in the diagnostics for this disease [55-57]. Noteworthy, in patients with coexisting lung diseases, such as emphysema or fibrosis, radiological features are less specific, and comparison with previous CT imaging is mandatory.

Altogether, the clinical and radiological characteristics observed in drug-related toxicities appear very similar to those induced by SARS-CoV-2 infection, thus generating a great challenge for oncologists and radiologist in distinguishing these entities; moreover, these specific diseases (without intravenous contrast) of a 64-year-old man with COVID-19 showing bilateral ground glass opacities someone with rounded morphology (yellow arrow) and interlobular septal thickening, predominantly located in the peripheral, near the fissures and posterior part of the lungs; vascular dilation is also seen (red arrows)

require very different therapeutic approaches. Naso-pharyngeal swabs and serology tests, as well bronchoscopy with bronchoalveolar lavage, are often crucial to discriminate infection from drug-toxicity; however, cytological examination can require time, and virological tests, despite the high specificity, do not have reliable sensitivity and are often unavailable for testing suspect patients in the world [9]. Unfortunately, standard chemotherapy does not seem to represent a suitable or potentially safer alternative to ICI or targeted therapy [5]. In fact, it must first be considered that targeting ICI alone or in combination to platinumbased chemotherapy has shown the best efficacy and now represents the standard of care for lung cancer patients not eligible to targeted therapy [58-62]. Second, the onset of chemotherapy- related pneumonitis has been reported in up to $16 \%$ of treated patients; moreover, cytotoxic agents have immunosuppressive activity that can make patients more susceptible to infection [63, 64]. Consistently, treatment with chemotherapy within the month preceding COVID-19 diagnosis has been reported to be associated with a higher risk of severe infection-related complications [65]. Based on the above considerations, it is crucial to inform the COVID-team (such as, pulmonologists, infectious disease specialists, anesthesiologists, radiologists) about of the type of anti-tumor treatment that patients received to aid in the differential diagnosis.

The tsunami of the pandemic has involved also the oncological research. Indeed, in the past year, most basic scientific researches have been curtailed/reshaped and have been prioritized those directed to SARS-CoV-2. Furthermore, it has been reported a $60 \%$ decrease in the new clinical trials 
for cancer drugs, and most ongoing studies have been temporarily suspended, as well as patient recruitment within studies, due to partial or total lockdowns imposed in various countries [66, 67]. To overcome these obstacles, the scientific community has rapidly gone virtual and has made a detour to remote platforms, thus facilitating the sharing of information in the most efficient way and bringing clinical research back to full operation [67].

\section{Lung Cancer Management in the COVID Era}

The dramatic impact that COVID-19 infection can have on lung cancer patients has highlighted the need to implement infection control measures and reorganize cancer management care [68]. As discussed above, data regarding the potential interference between cancer patients and COVID-19 infection are still not conclusive. Consequently, the dilemma for oncologists is how to balance the risk of COVID-19 exposure with delivering an active therapy and assistance to patients $[38,69-71]$. This complex task inevitably involves an emotional struggle for oncologists who on the one hand would like to treat patients, and on the other hand they are afraid of losing them due to COVID infection $[38,72,73]$. Along this line, oncologists have to preserve patients from COVID-19 infection, by limiting their access to the hospital unless strictly necessary, but they have also to guarantee a successful anticancer treatment, as the delay of cancer treatment could limit the efficacy of anti-tumor therapy and lead to cancer-related morbidity or even death of patients $[74,75]$. Similarly, lung cancer patients are living a stressful situation too, because they have an increased perception of their fragility, mainly due to the cancellation and rescheduling visits caused by the imposed self-isolation during the lockdown or telemedicine that substitutes the in-presence visits [10,73]. Given this very intricated clinical situation, since the outbreak, the main International Oncology Societies, including American Society of Clinical Oncology, European Society for Medical Oncology, and Italian Association of Medical Oncology, have proposed a variety of recommendations to help oncologists to safely guarantee the continuation of cancer treatments and to ensure the best standard of care (https://www.asco.org/asco-coron avirus-information, https://www.aiom.it/rischio-infettivoda-coronavirus-covid-19-indicazioni-aiom-comu-cipomoper-loncologia-2/) [76•]. These recommendations are mostly based on epidemic area, local healthcare structure capacity, individual risk of infection, stage of neoplastic disease, patient comorbidities, age, and treatment characteristics, and include relationship with the physician, indications of hygiene and protective measures anti-COVID-19, restrictions operated by cancer centers to prevent the spread of the virus [77]. Along this line, since the outbreak, a profound reorganization of (cancer) hospital has been done, and several precautions have been taken from the oncology community to protect cancer patients and ensure their safety while maintaining treatments. These measures include the following: (i) telemedicine service for the follow-up visits or other evaluations to reduce/limit the number of visits to the hospital and the consequent risk of infection and (ii) a triage system for all patients and their caregivers before entering hospital, including screening temperature checks and questionnaires. Along this line, at our center, all patients have to perform a rhino-oro-pharyngeal swabs before admitting to the hospital for cancer therapy, and this thanks to the availability of real-time PCR assays that can provide COVID-19 status results within an hour; thereby, a SARS-CoV-2 freezones has been created, ruling out infection in all patients and limiting access to their caregivers [78].

\section{Conclusions}

COVID-19 pandemic has strained and tested the resilience of worldwide healthcare systems in an unprecedented manner, thus generating profound changes, particularly in the cancer community. Along this line, pending antiviral therapeutic advances, including effective vaccines capable of halting the spread of SARS-CoV-2, every effort has been made by oncology community to rethink treatment pathways and strategies to protect cancer patients from COVID-19 infection and to avoid interruption of treatment.

Despite the reshaping of clinical and scientific activity in the pandemic era, some questions still remain open and will require quick clarification: (i) Asymptomatic, COVID19 infected lung cancer patients may continue or start anticancer therapy, including ICI? (ii) Lung cancer patients with post-COVID-19 pulmonary fibrosis may start/restart ICI therapy or targeted therapy? and what risks could we expect? (iii) Could COVID-19-induced pulmonary fibrosis represent a potential risk factor for secondary lung cancer? If so, should post-COVID-19 patients, especially those with pulmonary fibrosis, be monitored more closely? This is an important aspect to consider in light of the high percentage of COVID-19-infected patients worldwide. Dedicated clinical trials in lung cancer patients and COVID-19 co-infection are urgently needed to provide useful clarification on these topics.

Finally, building on lessons learned from the current pandemic, large-scale collaborations in the cancer community, which have proven effective in addressing the crisis quickly, should become an integral part of healthcare to improve and ensure the best quality of care for our patients. This can also be achieved through the use of information technology and other innovative approaches that can allow a faster exchange of scientific information and collaborations across borders. 


\section{Declarations}

Conflict of interest Luana Calabrò has received compensation for service as a consultant/advisory board member from Bristol-Myers Squibb, Roche, and MSD and has received compensation for educational activities from Bristol-Myers Squibb, Sanofi, and AstraZeneca. Giulia Rossi declares that she has no conflict of interest. Alessia Covre owns stock in Epigen Therapeutics S.r.l. Aldo Morra declares that he has no conflict of interest. Michele Maio has received compensation for service as a consultant/advisory board member from Bristol-Myers Squibb, Roche, MSD, Incyte Corporation, AstraZeneca, Merck Serono, Amgen, Laboratoires Pierre Fabre, Eli Lilly, GlaxoSmithKline, SciClone Pharmaceuticals, Sanofi, and Alfasigma and owns stock in Epigen Therapeutics S.r.l.

\section{References}

Papers of particular interest, published recently, have been highlighted as:

- Of importance

$\bullet$ Of major importance

1. Pollard CA, Morran MP, Nestor-Kalinoski AL. The COVID19 pandemic: a global health crisis. Physiol Genomics. 2020;52(11):549-57. https://doi.org/10.1152/physiolgenomics. 00089.2020 .

2. Li G, Fan Y, Lai Y, Han T, Li Z, Zhou P, et al. Coronavirus infections and immune responses. J Med Virol. 2020;92(4):424-32. https://doi.org/10.1002/jmv.25685.

3. Drosten C, Günther S, Preiser W, van der Werf S, Brodt $\mathrm{HR}$, Becker S, et al. Identification of a novel coronavirus in patients with severe acute respiratory syndrome. N Engl J Med. 2003;348(20):1967-76. https://doi.org/10.1056/NEJMoa0307 47.

4. Zaki AM, van Boheemen S, Bestebroer TM, Osterhaus AD, Fouchier RA. Isolation of a novel coronavirus from a man with pneumonia in Saudi Arabia. N Engl J Med. 2012;367(19):1814 20. https://doi.org/10.1056/NEJMoa1211721.

5. Calabrò L, Peters S, Soria JC, Di Giacomo AM, Barlesi F, Covre A, Altomonte M, et al. Challenges in lung cancer therapy during the COVID-19 pandemic. Lancet Respir Med. 2020;8(6):542-4. https://doi.org/10.1016/S2213-2600(20)30170-3.

6. World Health Organization. COVID-19: operational guidance for maintaining essential health services during an outbreak: interim guidance. 2020. 25 March 2020. World Health Organization. https://apps.who.int/iris/handle/10665/331561.

7.• Dumoulin DW, Gietema HA, Paats MS, Hendriks LEL, Cornelissen R. Differentiation of COVID-19 pneumonitis and ICI induced pneumonitis. Front Oncol. 2020;10:577696. https://doi. org/10.3389/fonc.2020.577696. eCollection 2020. The article summarizes the clinical and radiological features of COVIDpneumonitis and ICI-related lung toxicity and suggests a diagnostic algorithm for distinguishing the two entities.

8. Rothstein MA, Parmet WE, Reiss DR. Employer-mandated vaccination for COVID-19. Am J Public Health. 2021;e1-e4. https://doi.org/10.2105/AJPH.2020.306166.

9. Catania C, Stati V, Spitaleri G. Interstitial pneumonitis in the COVID-19 era: a difficult differential diagnosis in patients with lung cancer. Tumori. 2020;300891620951863. https://doi.org/ $10.1177 / 0300891620951863$.
10. Vivarelli S, Falzone L, Grillo CM, Scandurra G, Torino F, Libra M. Cancer management during COVID-19 pandemic: is immune checkpoint inhibitors-based immunotherapy harmful or beneficial? Cancers (Basel). 2020;12(8):2237. https://doi.org/10.3390/ cancers12082237.

11.•• Vabret N, Britton GJ, Gruber C, Hegde S, Kim J, Kuksin M, et al. Sinai immunology review project. Immunology of COVID19: Current State of the Science. Immunity. 2020;52(6):910-41. https://doi.org/10.1016/j.immuni.2020.05.002. This article synthesizes the immune response to SARS-CoV-2 infection and the immunological pathways that likely contribute to disease severity of COVID-19.

12. Chibber P, Haq SA, Ahmed I, Andrabi NI, Singh G. Advances in the possible treatment of COVID-19: a review. Eur J Pharmacol. 2020;883:173372. https://doi.org/10.1016/j.ejphar.2020.173372.

13. Jean SS, Hsueh PR. Old and re-purposed drugs for the treatment of COVID-19. Expert Rev Anti Infect Ther. 2020;18(9):843-7. https://doi.org/10.1080/14787210.2020.1771181.

14. Wiersinga WJ, Rhodes A, Cheng AC, Peacock SJ, Prescott HC. Pathophysiology, transmission, diagnosis, and treatment of coronavirus disease 2019 (COVID-19): a review. JAMA. 2020;324(8):782-93. https://doi.org/10.1001/jama.2020.12839. The review summarizes the current evidences regarding the pathophysiology, transmission, diagnosis, and management of COVID-19.

15. Parasher A. COVID-19: Current understanding of its pathophysiology, clinical presentation and treatment. Postgrad Med J. 2020;postgradmedj-2020-138577. https://doi.org/10.1136/ postgradmedj-2020-138577.

16. Dong $\mathrm{M}$, Zhang J, Ma X, Tan J, Chen L, Liu S, et al. ACE2, TMPRSS2 distribution and extrapulmonary organ injury in patients with COVID-19. Biomed Pharmacother. 2020;131:110678. https://doi.org/10.1016/j.biopha.2020. 110678.

17. Evans PC, Rainger GE, Mason JC, Guzik TJ, Osto E, Stamataki Z, et al. Endothelial dysfunction in COVID-19: a position paper of the ESC working group for atherosclerosis and vascular biology, and the ESC council of basic cardiovascular science. Cardiovasc Res. 2020;116(14):2177-84. https://doi.org/10.1093/ cvr/cvaa230.

18. Wang B, Wang L, Kong X, Geng J, Xiao D, Ma C, et al. Longterm coexistence of SARS-CoV-2 with antibody response in COVID-19 patients. J Med Virol. 2020;92(9):1684-9. https:// doi.org/10.1002/jmv.25946.

19. Haveri A, Smura T, Kuivanen S, Österlund P, Hepojoki J, Ikonen $\mathrm{N}$, et al. Serological and molecular findings during SARS-CoV-2 infection: the first case study in Finland, January to February 2020. Euro Surveill. 2020;25(11):2000266. https://doi.org/10. 2807/1560-7917.ES.2020.25.11.2000266.

20. Luo J, Rizvi H, Preeshagul IR, Egger JV, Hoyos D, Bandlamudi $\mathrm{C}$, et al. COVID-19 in patients with lung cancer. Ann Oncol. 2020;31(10):1386-96. https://doi.org/10.1016/j.annonc.2020. 06.007 .

21. Okba NMA, Widjaja I, Li W, GeurtsvanKessel CH, Farag EABA, Al-Hajri M, et al. Serologic detection of Middle East Respiratory Syndrome coronavirus functional antibodies. Emerg Infect Dis. 2020;26(5):1024-7. https://doi.org/10.3201/eid2605. 190921.

22. Zhao J, Yuan Q, Wang H, Liu W, Liao X, Su Y, et al. Antibody responses to SARS-CoV-2 in patients with novel coronavirus disease 2019. Clin Infect Dis. 2020;71(16):2027-34. https://doi. org/10.1093/cid/ciaa344.

23. Chowdhury MA, Hossain N, Kashem MA, Shahid MA, Alam A. Immune response in COVID-19: a review. J Infect Public Health. 2020;13(11):1619-29. https://doi.org/10.1016/j.jiph. 2020.07.001. 
24. Zheng M, Gao Y, Wang G, Song G, Liu S, Sun D, et al. Functional exhaustion of antiviral lymphocytes in COVID-19 patients. Cell Mol Immunol. 2020;17(5):533-5. https://doi. org/10.1038/s41423-020-0402-2.

25. Chen G, Wu D, Guo W, Cao Y, Huang D, Wang H, Wang T, Zhang X, Chen H, Yu H, Zhang X, Zhang M, Wu S, Song J, Chen T, Han M, Li S, Luo X, Zhao J, Ning Q. Clinical and immunological features of severe and moderate coronavirus disease 2019. J Clin Invest. 2020;130(5):2620-9. https://doi. org/10.1172/JCI137244.

26. Wang Y, Liu Y, Liu L, Wang X, Luo N, Li L. Clinical outcomes in 55 patients with severe acute respiratory syndrome coronavirus 2 who were asymptomatic at hospital admission in Shenzhen. China J Infect Dis. 2020;221(11):1770-4. https:// doi.org/10.1093/infdis/jiaa119.

27. Zeng Q, Li YZ, Huang G, Wu W, Dong SY, Xu Y. Mortality of COVID-19 is associated with cellular immune function compared to immune function in Chinese Han population. medRxiv. 2020. https://doi.org/10.1101/2020.03.08.20031229.

28. Diao B, Wang C, Tan Y, Chen X, Liu Y, Ning L, et al. Reduction and functional exhaustion of $\mathrm{T}$ cells in patients with coronavirus disease 2019 (COVID-19). Front Immunol. 2020;11:827. https://doi.org/10.3389/fimmu.2020.00827. eCollection 2020.

29. Zhou Y, Fu B, Zheng X, Wang D, Zhao C, Qi Y, et al. Pathogenic $\mathrm{T}$ cells and inflammatory monocytes incite inflammatory storm in severe COVID-19 patients. Natl Sci Rev. 2020. Published online March 13, 2020. https://doi.org/10.1093/nsr/ nwaa041.

30. Qin C, Zhou L, Hu Z, Zhang S, Yang S, Tao Y, et al. Dysregulation of immune response in patients with coronavirus 2019 (COVID-19) in Wuhan. China Clin Infect Dis. 2020;71(15):7628. https://doi.org/10.1093/cid/ciaa248.

31. Tan J, Yang C. Prevention and control strategies for the diagnosis and treatment of cancer patients during the COVID-19 pandemic. Br J Cancer. 2020;123(1):5-6. https://doi.org/10.1038/ s41416-020-0854-2.

32. Garassino MC, Whisenant JG, Huang LC, Trama A, Torri V, Agustoni F, et al. COVID-19 in patients with thoracic malignancies (TERAVOLT): first results of an international, registrybased, cohort study. Lancet Oncol. 2020;21(7):914-22. https:// doi.org/10.1016/S1470-2045(20)30314-4. The article reports preliminary results of the COVID-19 impact on thoracic cancer patients and indentifies predictive factors of worse outcome to COVID-19 infection.

33. Wang H, Zhang L. Risk of COVID-19 for patients with cancer. Lancet Oncol. 2020;21(4):e181. https://doi.org/10.1016/S14702045(20)30149-2.

34. Gonzalez H, Hagerling C, Werb Z. Roles of the immune system in cancer: from tumor initiation to metastatic progression. Genes Dev. 2018;32(19-20):1267-84. https://doi.org/10.1101/ gad.314617.118.

35. Wargo JA, Reuben A, Cooper ZA, Oh KS, Sullivan RJ. Immune effects of chemotherapy, radiation, and targeted therapy and opportunities for combination with immunotherapy. Semin Oncol. 2015;42(4):601-16. https://doi.org/10.1053/j.semin oncol.2015.05.007.

36. Zhang JJY, Lee KS, Ang LW, Leo YS, Young BE. Risk factors for severe disease and efficacy of treatment in patients infected with COVID-19: a systematic review, meta-analysis, and metaregression analysis. Clin Infect Dis. 2002;71(16):2199-206. https://doi.org/10.1093/cid/ciaa576.

37. Zhang H, Quek K, Chen R, Chen J, Chen B. Expression of the SAR2-Cov-2 receptor ACE2 reveals the susceptibility of COVID-19 in non-small cell lung cancer. J Cancer. 2020;11(18):5289-92. https://doi.org/10.7150/jca.49462.
38. Sha Z, Chang K, Mi J, Liang Z, Hu L, Long F, et al. The impact of the COVID-19 pandemic on lung cancer patients. Ann Palliat Med. 2020;9(5):3373-8. https://doi.org/10.21037/ apm-20-1662.

39. Dai M, Liu D, Liu M, Zhou F, Li G, Chen Z, et al. Patients with cancer appear more vulnerable to SARS-CoV-2: a multicenter study during the COVID-19 outbreak. Cancer Discov. 2020;10(6):783-91. https://doi.org/10.1158/2159-8290. CD-20-0422.

40. Rugge M, Zorzi M, Guzzinati S. SARS-CoV-2 infection in the Italian Veneto region: adverse outcomes in patients with cancer. Nat Cancer. 2020. https://doi.org/10.1038/s43018-020-0104-9.

41. Luo J, Rizvi H, Preeshagul IR, Egger JV, Hoyos D, Bandlamudi $\mathrm{C}$, et al. COVID-19 in patients with lung cancer. Ann Oncol. 2020;31(10):1386-96. https://doi.org/10.1016/j.annonc.2020. 06.007 .

42.•• Maio M, Hamid O, Larkin J, Covre A, Altomonte M, Calabrò $\mathrm{L}$, et al. Immune checkpoint inhibitors for cancer therapy in the COVID-19 era. Clin Cancer Res. 2020;26(16):4201-5. https:// doi.org/10.1158/1078-0432.CCR-20-1657. The article discusses on the potential interference of anti-tumor drugs, especially immune checkpoint inhibitors on the SARS-CoV-2 infection, and suggests guidance for treating physicians during COVID-19 pandemic.

43. Wherry EJ, Ha SJ, Kaech SM, Haining WN, Sarkar S, Kalia V, et al. Molecular signature of CD8+ T cell exhaustion during chronic viral infection. Immunity. 2007;27(4):670-84. https:// doi.org/10.1016/j.immuni.2007.09.006.

44. McLane LM, Abdel-Hakeem MS, Wherry EJ. CD8 T cell exhaustion during chronic viral infection and cancer. Annu Rev Immunol. 2019;37:457-95. https://doi.org/10.1146/annurevimmunol-041015-055318.

45. Shah NJ, Al-Shbool G, Blackburn M, Cook M, Belouali A, Liu SV, et al. Safety and efficacy of immune checkpoint inhibitors (ICIs) in cancer patients with HIV, hepatitis B, or hepatitis C viral infection. J Immunother Cancer. 2019;7(1):353. https://doi. org/10.1186/s40425-019-0771-1.

46. Pu D, Yin L, Zhou Y, Li W, Huang L, Cai L, et al. Safety and efficacy of immune checkpoint inhibitors in patients with HBV/ HCV infection and advanced-stage cancer: a systematic review. Medicine (Baltimore). 2020;99(5): e19013. https://doi.org/10. 1097/MD.0000000000019013.

47. El-Khoueiry AB, Sangro B, Yau T, Crocenzi TS, Kudo M, Hsu $\mathrm{C}$, et al. Nivolumab in patients with advanced hepatocellular carcinoma (CheckMate 040): an open-label, non-comparative, phase $1 / 2$ dose escalation and expansion trial. Lancet. 2017;389(10088):2492-502. https://doi.org/10.1016/S01406736(17)31046-2.

48. Nishino M, Ramaiya NH, Awad MM, Sholl LM, Maattala JA, Taibi M, et al. PD-1 Inhibitor-related pneumonitis in advanced cancer patients: radiographic patterns and clinical course. Clin Cancer Res. 2016;22(24):6051-60. https://doi.org/10.1158/ 1078-0432.CCR-16-1320.

49. Naidoo J, Wang X, Woo KM, Iyriboz T, Halpenny D, Cunningham $\mathrm{J}$, et al. Pneumonitis in patients treated with anti-programmed death-1/programmed death ligand 1 therapy. J Clin Oncol. 2017;35(7):709-17. https://doi.org/10.1200/JCO.2016. 68.2005.

50. Suresh K, Voong KR, Shankar B, Forde PM, Ettinger DS, Marrone KA, et al. Pneumonitis in non-small cell lung cancer patients receiving immune checkpoint immunotherapy: incidence and risk factors. J Thorac Oncol. 2018;13(12):1930-9. https://doi.org/10.1016/j.jtho.2018.08.2035.

51. Soria JC, Ohe Y, Vansteenkiste J, Reungwetwattana T, Chewaskulyong B, Lee $\mathrm{KH}$, et al. Osimertinib in untreated 
EGFR-mutated advanced non-small-cell lung cancer. N Engl J Med. 2018;378(2):113-25. https://doi.org/10.1056/NEJMoa1713.

52. Nishino M, Suda K, Kobayashi Y, Ohara S, Fujino T, Koga T, Chiba M, Shimoji M, Tomizawa K, Takemoto T, Mitsudomi T. Effects of secondary EGFR mutations on resistance against upfront osimertinib in cells with EGFR-activating mutations in vitro. Lung Cancer. 2018;126:149-55. https://doi.org/10.1016/j.lungcan.2018. 10.026 .

53. Som A, Lang M, Little B. Pulmonary vascular pathology in Covid19. N Engl J Med. 2020;383(9):887. https://doi.org/10.1056/ NEJMc2022068.

54. Prokop M, van Everdingen W, van Rees Vellinga T, Quarles van Ufford H, Stöger L, Beenen L, et al. CO-RADS: a categorical CT assessment scheme for patients suspected of having COVID19-definition and evaluation. Radiology. 2020;296(2):E97-104. https://doi.org/10.1148/radiol.2020201473.

55. Klok FA, Kruip MJHA, van der Meer NJM, Arbous MS, Gommers DAMPJ, Kant KM, et al. Incidence of thrombotic complications in critically ill ICU patients with COVID-19. Thromb Res. 2020;191:145-7. https://doi.org/10.1016/j.thromres.2020.04.013.

56. Poyiadji N, Cormier P, Patel PY, Hadied MO, Bhargava P, Khanna $\mathrm{K}$, et al. Acute pulmonary embolism and COVID-19. Radiology. 2020;297(3):E335-8. https://doi.org/10.1148/radiol.2020201955.

57. Revel MP, Parkar AP, Prosch H, Silva M, Sverzellati N, Gleeson F, et al. COVID-19 patients and the radiology department - advice from the European Society of Radiology (ESR) and the European Society of Thoracic Imaging (ESTI). Eur Radiol. 2020;30(9):4903-9. https://doi.org/10.1007/s00330-020-06865-y.

58 Dafni U, Tsourti Z, Vervita K, Peters S. Immune checkpoint inhibitors, alone or in combination with chemotherapy, as first-line treatment for advanced non-small cell lung cancer. A systematic review and network meta-analysis. Lung Cancer. 2019;134:127-40. https://doi.org/10.1016/j.lungcan.2019.05.029.

59. Paz-Ares L, Ciuleanu TE, Cobo M, Schenker M, Zurawski B, Menezes J, et al. First-line nivolumab plus ipilimumab combined with two cycles of chemotherapy in patients with non-small-cell lung cancer (CheckMate 9LA): an international, randomised, openlabel, phase 3 trial. Lancet Oncol. 2021;22(2):198-211. https:// doi.org/10.1016/S1470-2045(20)30641-0.

60. Hellmann MD, Paz-Ares L, Bernabe Caro R, Zurawski B, Kim SW, Carcereny Costa E, et al. Nivolumab plus ipilimumab in advanced non-small-cell lung cancer. N Engl J Med. 2019;381(21):2020-31. https://doi.org/10.1056/NEJMoa1910231.

61. Horn L, Mansfield AS, Szczęsna A, Havel L, Krzakowski M, Hochmair MJ, et al. First-line atezolizumab plus chemotherapy in extensive-stage small-cell lung cancer. N Engl J Med. 2018;379(23):2220-9. https://doi.org/10.1056/NEJMoa1809064.

62. Paz-Ares L, Dvorkin M, Chen Y, Reinmuth N, Hotta K, Trukhin $\mathrm{D}$, et al. Durvalumab plus platinum-etoposide versus platinumetoposide in first-line treatment of extensive-stage small-cell lung cancer (CASPIAN): a randomised, controlled, open-label, phase 3 trial. Lancet. 2019;394(10212):1929-39. https://doi.org/10.1016/ S0140-6736(19)32222-6.

63. Magee DE, Hird AE, Klaassen Z, Sridhar SS, Nam RK, Wallis CJD, et al. Adverse event profile for immunotherapy agents compared with chemotherapy in solid organ tumors: a systematic review and meta-analysis of randomized clinical trials. Ann Oncol. 2020;31(1):50-60. https://doi.org/10.1016/j.annonc.2019.10.008.

64. Lehne G, Lote K. Pulmonary toxicity of cytotoxic and immunosuppressive agents. A review. Acta Oncol. 1990;29(2):113-24. https:// doi.org/10.3109/02841869009126530.

65. Liang W, Guan W, Chen R, Wang W, Li J, Xu K, Li C, Ai Q, Lu W, Liang H, Li S, He J. Cancer patients in SARS-CoV-2 infection: a nationwide analysis in China. Lancet Oncol. 2020;21(3):335-7. https://doi.org/10.1016/S1470-2045(20)30096-6.

66. Wilkinson E. Dramatic drop in new cancer drug trials during the COVID-19 pandemic. Lancet Oncol. 2021:S1470-2045(21)00067X. https://doi.org/10.1016/S1470-2045(21)00067-X.

67. Barroga E, Mitoma H. Critical thinking and scientific writing skills of non-Anglophone medical students: a model of training course. J Korean Med Sci. 2019;34(3):e18. doi: https://doi.org/10.3346/ jkms.2019.34.e18. eCollection 2019 Jan 21.

68. Jazieh AR, Akbulut H, Curigliano G, Rogado A, Alsharm AA, Razis ED, Mula-Hussain L, Errihani H, Khattak A, De Guzman RB, Mathias C, Alkaiyat MOF, Jradi H, Rolfo C. International research network on COVID-19 impact on cancer care. Impact of the COVID-19 pandemic on cancer care: a global collaborative study. JCO Glob Oncol. 2020;6:1428-38. https://doi.org/10.1200/ GO.20.00351.

69. Burki TK. Cancer guidelines during the COVID-19 pandemic. Lancet Oncol. 2020;21(5):629-30. https://doi.org/10.1016/S14702045(20)30217-5.

70 Emanuel EJ, Persad G, Upshur R, Thome B, Parker M, Glickman A, et al. Fair allocation of scarce medical resources in the time of Covid-19. N Engl J Med. 2020;382(21):2049-55. https://doi.org/ 10.1056/NEJMsb2005114.

71. Kutikov A, Weinberg DS, Edelman MJ, Horwitz EM, Uzzo RG, Fisher RI. A war on two fronts: cancer care in the time of COVID19. Ann Intern Med. 2020;172(11):756-8. https://doi.org/10.7326/ M20-1133.

72. Lewis MA. Between Scylla and Charybdis - oncologic decision making in the time of Covid-19. N Engl J Med. 2020;382(24):2285-7. https://doi.org/10.1056/NEJMp2006588.

73. Schade EC, Elkaddoum R, Kourie HR. The psychological challenges for oncological patients in times of COVID-19 pandemic: telemedicine, a solution? Future Oncol. 2020;16(29):2265-8. https://doi.org/10.2217/fon-2020-0552.

74. Hanna TP, Evans GA, Booth CM. Cancer, COVID-19 and the precautionary principle: prioritizing treatment during a global pandemic. Nat Rev Clin Oncol. 2020;17(5):268-70. https://doi.org/10. 1038/s41571-020-0362-6.

75. Lambertini M, Toss A, Passaro A, Criscitiello C, Cremolini C, Cardone $\mathrm{C}$, et al. Cancer care during the spread of coronavirus disease 2019 (COVID-19) in Italy: young oncologists' perspective. ESMO Open. 2020;5(2):e000759. https://doi.org/10.1136/esmoo pen-2020-000759.

76. Passaro A, Addeo A, Von Garnier C, Blackhall F, Planchard D, Felip E, et al. ESMO Management and treatment adapted recommendations in the COVID-19 era: Lung cancer. ESMO Open. 2020;5(Suppl 3):000820. https://doi.org/10.1136/esmoopen-2020000820 . The article summarizes the main recommendations by the European Society of Medical Oncology to maintain the highest possible standards in the management of lung cancer patients in the pandemic era.

77. Addeo A, Friedlaender A. Cancer and COVID-19: unmasking their ties. Cancer Treat Rev. 2020;88:102041. https://doi.org/10.1016/j. ctrv.2020.102041.

78. https://www.fda.gov/medical-devices/emergencysituations-medic al-devices/emergency-use-authorizations. Accessed April 2, 2020.

Publisher's note Springer Nature remains neutral with regard to jurisdictional claims in published maps and institutional affiliations. 